\title{
A Case Study of Imagery Rehearsal Therapy in a Nightmare Disorder Patient with Posttraumatic Stress Disorder
}

\author{
Soyeong Park ${ }^{1}$, Su Jung Choi ${ }^{2,3}$, Eun Yeon Joo ${ }^{3}$, Sooyeon Suh ${ }^{1}$ \\ ${ }^{1}$ Department of Psychology, Sungshin Women's University, Seoul, \\ ${ }^{2}$ Department of Nursing, Samsung Medical Center, Department of Clinical Nursing Science, Sungkyunkwan University School of Medicine, Seoul, \\ ${ }^{3}$ Department of Neurology, Brain-Nerve Center, Samsung Medical Center, Samsung Biomedical Research Institute (SBRI), \\ Sungkyunkwan University School of Medicine, Seoul, Korea
}

\author{
외상후 스트레스 장애가 있는 악몽장애 환자의 심상시연치료 사례 \\ 박소영 ${ }^{1}$, 최수정 ${ }^{2,3}$, 주은연 ${ }^{3}$, 서수연 ${ }^{1}$ \\ 성신여자대학교 심리학과, ${ }^{1}$ 성균관대학교 임상간호대학원, 삼성서울병원 간호부, ${ }^{2}$ \\ 성균관대학교 의과대학 신경과학교실, 삼성서울병원 뇌신경센터 ${ }^{3}$
}

$\begin{array}{ll}\text { Received } & \text { May 1, 2019 } \\ \text { Revised } & \text { May 31, 2019 } \\ \text { Accepted } & \text { May 31, 2019 }\end{array}$

Address for correspondence

Sooyeon Suh, PhD

Department of Psychology,

Sungshin Women's University,

2 Bomun-ro 34da-gil,

Seongbuk-gu,

Seoul 02844, Korea

Tel: $+82-2-920-7215$

Fax: +82-2-920-2040

E-mail: alysuh@sungshin.ac.kr
Nightmares are vivid, unpleasant dreams that result in awakening during sleep. According to previous studies, the prevalence of nightmare disorder is $2-5 \%$ of the general population and is associated with other medical conditions and mental illnesses. Imagery rehearsal therapy (IRT) is an evidence-based treatment for nightmare disorder. The current study is a case study with a 35-year-old female who was diagnosed with nightmare disorder and posttraumatic stress disorder, and participated in IRT for five sessions. Prior to treatment, the patient reported difficulties initiating and maintaining sleep, and reported suffering from nightmares more than 2-3 times per week. After treatment, the patient reported no longer experienced nightmares, accompanied by improvements in both sleep and clinical indicators.

J Sleep Med 2019;16(1):61-66

Key Words: Nightmare, Imagery rehearsal therapy, Insomnia.
악몽이란 정신장애 진단 및 통계 편람(Diagnostic and Statistical Manual of mental disorders Fifth edition, DSM5)에 의하면 “생존, 안전, 신체적 온전함에 대한 위협을 피하 고자 노력하는 광범위하고 극도로 불쾌하며 생생하게 기억 나는 꿈”을 의미한다. ${ }^{1}$ 이러한 악몽은 급속안구운동(rapid eye movement) 수면 중에 발생하고 수면 후반부에 나타날 가능성이 높다. ${ }^{1}$ 악몽은 수면 도중 각성을 일으켜 기상으로 종료되며, 기상 후 빠르게 지남력을 회복한다. 그러나 악몽 에서 경험한 불안, 공포와 같은 불쾌한 감정은 기상 후에 지 속되기도 하며, 다시 수면을 취하기 어렵게 하거나 낮 동안의 기능에 손상 및 고통을 줄 수 있다. 악몽은 외상을 겪은 직후, 개인에게 의미 있고 중요한 세부사항을 기억하게 함으로써

This is an Open Access article distributed under the terms of the Creative Commons Attribution Non-Commercial License (https://creativecommons.org/licenses/by-nc/4.0) which permits unrestricted non-commercial use, distribution, and reproduction in any medium, provided the original work is properly cited.
정서적인 처리에 유용한 정보를 제공하고, 안전한 곳에 머무 를 수 있도록 동기 부여함으로써 생존을 위한 적응적인 기 능을 제공한다. ${ }^{2}$ 그러나 시간이 지나 안전한 환경임에도 불 구하고 악몽이 반복적으로 발생한다면 수면 분절을 경험하 고 고통을 주어 적응적 가치가 떨어진다. 행동주의적 관점에 서 악몽은 외상을 겪은 후 발생하는 비자발적인 행동이며, 반복을 통해 학습된 습관이다. ${ }^{3}$

악몽은 성인의 $85 \%$ 가 1년에 한 번 정도 경험하며, 2 6\% 의 사람들이 일주일에 한 번 정도 경험한다고 알려져 있다. ${ }^{4}$ 특히 악몽은 남성보다 여성에게서 더 자주 나타나고, 다른 의학적 상태 및 정신질환과 동반될 수 있으며, 청소년기 후 반이나 성인기 초기에 유병률과 심각도가 최고에 이른다. ${ }^{1}$ 빈번한 악몽 경험은 불안, 우울, 자살 위험과 같이 부적응적 인 문제와 관련이 있음에도 불구하고 대체적으로 임상 현장 에서는 별도로 악몽장애에 대한 치료적 개입이 부족하다. 이 
에 본 연구에서는 악몽에 대한 근거기반 치료인 심상시연치 료(imagery rehearsal therapy, IRT)를 시행하였다. 심상시 연치료는 외상 후 스트레스 장애(posttraumatic stress disorder, PTSD), 우울장애, 불면증, 알코올사용장애 등 정신질환 환자들에게 효과적으로 악몽을 치료하기 위해 시행되고 있 으며, 반복적으로 효과성을 검증한 바 있다. ${ }^{5}$ 특히 PTSD를 겪는 참전 군인들을 대상으로 하여 심상시연치료를 실시하 였을 때, 악몽 빈도와 강도, 우울 증상이 유의미하게 감소됨을 확인하였다. 또한 성폭행 피해자들에게 심상시연치료를 실 시한 결과 악몽 빈도, 수면의 질, PTSD 증상의 심각도에 있 어 호전되었고, 3개월 후 추적 조사 결과 통제군에 비해 유 의미한 수준으로 치료 효과가 지속된 것을 확인하였다.

심상시연치료란 악몽은 학습된 행동으로 가정하여, 내담 자에게 악몽 및 수면 교육을 제공하고, 심상을 통해 악몽을 재구성하여 새로운 꿈으로 대체한 후, 새로운 인지적 습관 형성을 위해 연습하는 과정을 거친다. 심상시연치료는 학습 된 악몽을 효과적으로 소거하기 위해 심상을 활용하여 악몽 내용을 재구성하며, 이러한 작업을 통해 악몽을 감소시킨 다. ${ }^{2}$ 심상시연치료는 내용에 대한 노출과 반복된 시연을 통 해 공포 소거 기억에 대한 재학습을 시키는 원리를 기반으 로 한다. 새로운 맥락에서 악몽을 재구성하는 심상을 통해 공포 기억이 소거될 수 있으며, 이러한 원리는 Milad와 그 외 연구진(2005)의 공포 소거 실험을 바탕으로 치료가 응용 이 된 것이다. ${ }^{6}$ 실험을 통해 공포 조건화한 맥락과 소거 맥락 에 따라 시간이 지연된 이후에도 조건 반응이 유의한 차이 가 있음을 확인하였다. 즉, 심상시연치료는 맥락이 소거 기 억을 조절할 수 있다는 원리를 통해 새로운 스크립트의 꿈 으로 악몽을 재구성하여 공포 기억을 소거할 수 있다.

본 연구는 국내에서 처음으로 악몽장애 및 $\mathrm{PTSD}$ 공존 환 자에게 심상시연치료를 실시한 증례에 대해 보고한다.

\section{증 례}

\section{내담자의 정보}

내담자는 35세 여성으로 2년 전부터 지속되는 악몽을 반 복적으로 꾼다고 호소하며 내원하였다. 내담자는 3년 전 교 제했던 남성으로부터 지속적인 신체적, 언어적 폭력 및 성폭 력을 경험하였고, 이후 가해자가 내담자에게 폭력을 가하는 내용의 악몽을 반복적으로 꾸었다. 내담자는 외상 경험 이후 성폭력 상담센터 및 병원을 통해 외상 후 스트레스 장애 치 료와 약물 처방을 받았다. 그러나 치료 전에 비해 호전됨을 느끼지 못하였고, 현재까지 악몽 증상은 나아지지 않은 상태 라고 보고하였다. 현재 미혼인 내담자는 어머니와 언니들과
함께 거주하고 있으며, 내담자는 가족에 대한 스트레스도 함 께 호소하였다.

\section{치료 전 평가}

치료 전 내담자를 평가하기 위해 DSM- IV 의 제I축 장애 의 구조화된 임상적 면담, Structured Clinical Interview for DSM-IV Axis 1 Disorders, Research Version을 실시한 바 내담자는 정신증적 증상 및 물질 사용장애 진단 기준에 해 당되지 않았다. Lee와 Shin(1993)이 표준화한 간이정신상태 검사 Mini Mental State Examination의 내담자 점수는 30점 으로 인지기능에 손상이 없는 것으로 나타났다. ${ }^{7} \mathrm{DSM}-5$ 악 몽장애 진단 기준을 토대로 반구조화된 악몽장애 면담을 실 시한 결과 내담자는 악몽장애로 진단 가능하였다. 내담자의 악몽 심각도를 측정하는 Disturbing Dream and Nightmare Severity Index 점수는 15점으로 악몽 임상군으로 나타났으 며, 악몽으로 인한 기능 손상을 측정하는 Nightmare Effects Survey 점수는 10 점으로 기능 손상이 있음을 확인하였다. 면담 시 내담자의 주관적인 보고에 따르면 내담자는 외상 사건 이후 악몽을 2년 동안 경험하였다고 보고하였고, 악몽 으로 인해 입면, 수면 유지의 어려움, 조기 기상에 대해 어려 움을 호소하였다. 내담자는 수면 중 악몽으로 인해 각성이 되면 다시 잠들지 못하는 경우가 대다수이며, 잠에 들더라도 1 2시간 후 일어난다고 보고하였다. 내담자가 주간에 스트 레스를 받는 경우 매일 똑같은 악몽을 3 4번 경험하였으며, 주간에 집중의 어려움을 호소하였다. 내담자의 불면증 심각 도 질문지 Insomnia Severity Index 점수는 20점으로 내담 자는 중등도의 불면증을 겪고 있으며, 실제 잠에 들기까지 평균 2.4시간 정도 걸려 잠자리에 일찍 들어간다고 보고하였 다. 내담자의 주관적인 보고로 외상 사건 이후 3년 동안 제 대로 수면을 취하지 못하였으며, 하루에 3시간도 채 잠을 자 지 못한다고 하였다. 면담 이후, 내담자의 수면에 대해 더 자 세히 평가하기 위하여 수면 및 악몽 일지를 과제로 내주어 작성하도록 하였다.

임상가를 위한 PTSD 척도 Clinician-Administered PTSD Scale for DSM-5에서 심각도 53점으로 DSM-5의 진단 기 준을 모두 충족하여 PTSD 또한 진단 가능하였다. 자가 보고 형식의 PTSD 증상 심각도를 알 수 있는 PTSD Checklist for DSM-5 결과 48점으로 PTSD 임상군으로 나타났다. 내 담자의 우울과 불안을 측정하기 위해 Beck Depression Inventory, Beck Anxiety Inventory 질문지를 실시한 결과 24 점, 25점으로 내담자는 중등도의 우울과 불안을 경험하였다. 자살 심각도를 평가하는 Depressive Symptom Inventory 점 수는 4점으로 높은 자살 위험성을 보였다. 


\section{치료 내용}

\section{치료 진행}

내담자 대상으로 심상시연치료는 총 5 회기 실시되었으며, 주 1 회, 50 분 동안 진행하였다. 치료 기간 동안 내담자는 수 면 및 악몽일지를 매일, 5 주간 작성하였다. 수면 및 악몽 일 지는 수면에 대한 자세한 지표(수면 잠복기, 취침 시간, 입면 후 각성 시간 등)와 매일 악몽의 횟수를 기록하는 일지이다. 치료 전에 항상 수면 및 악몽 일지를 점검하고, 치료 1 회기 와 5 회기에 임상지표에 대한 자기보고식 질문지를 작성하는 시간을 가졌다. 심상시연치료의 회기별 진행 내용은 Table 1 에 제시되었다.

\section{1 회기}

1 회기에서는 치료자와 내담자의 라포 형성 및 내담자의 수면과 악몽 상태를 검토하고, 심상시연치료에 대한 소개가 진행되었다. 심상시연치료의 첫 회기는 주로 내담자의 수면
에 대한 평가를 면담 형식으로 진행하였다. 내담자는 주 2 3회 이상 악몽을 꾼다고 보고하였으며, 이로 인한 상당한 정서적 고통 및 다음 날 기능 손상을 호소하였다. 악몽에서 깨고 난 이후 다시 잠들 때에는 같은 내용의 악몽을 하루에 2 3번 꾼다고 보고하였다. 내담자의 보고에 따르면 악몽으 로 인해 쉽게 수면을 취하지 못하고, 잠에 들더라도 1 2시 간을 채 유지하지 못한다고 호소하였다. 내담자는 평소 낮잠 을 자지 않으며 주간에 졸림을 경험하지 않으나, 악몽으로 인해 하루 종일 멍하고 이전의 외상 사건들에 대한 침습 증 상 및 플래시백과 같은 외상 후 스트레스 장애 증상을 보고 하였다. 이에 내담자는 치료 목표를 "잠을 5 6시간 정도 잘 자고 싶다”고 하였으며, 과제로 수면 및 악몽 일지 작성을 내주었다.

\section{2회기}

1 회기에서 교육받은 심상시연치료에 대해 복습을 하고, 작성해 온 수면 및 악몽 일지를 검토하였다. 검토 결과 내담

Table 1. IRT session topics

\begin{tabular}{|c|c|}
\hline Session & Topics \\
\hline 1 session & $\begin{array}{l}\text { - Introduction of the therapist } \\
\text { - Checking the nightmare experience and sleep status of the patients } \\
\text { - Introduction to IRT } \\
\text { - Homework assignments: Writing a sleep and nightmare diary } \\
\text { - Question and review }\end{array}$ \\
\hline 2 session & $\begin{array}{l}\text { - Review last session } \\
\text { - Common concerns about IRT } \\
\text { - Checking the sleep and nightmare diary } \\
\text { - Facts about sleep and nightmares } \\
\text { - Breath } \\
\text { - Practice pleasant imagery } \\
\text { - Homework assignments: Writing a sleep and nightmare diary, practice pleasant imagery } \\
\text { - Question and review }\end{array}$ \\
\hline 3 session & $\begin{array}{l}\text { - Checking the sleep and nightmare diary } \\
\text { - Pleasant imagery practice review } \\
\text { - Nightmare rescript } \\
\text { - Homework assignments: Practice imagery rehearsal, writing a sleep and nightmare diary } \\
\text { - Question and review }\end{array}$ \\
\hline 4 session & $\begin{array}{l}\text { - Checking the sleep and nightmare diary } \\
\text { - Rescripted dream imagery review } \\
\text { - Homework assignments: Practice rescripted dream imagery rehearsal, writing a sleep and nightmare diary } \\
\text { - Question and review }\end{array}$ \\
\hline 5 session & $\begin{array}{l}\text { - Checking the sleep and nightmare diary } \\
\text { - Rescripted dream imagery review } \\
\text { - Relapse prevention: Identifying triggers, demonstration of skill knowledge, application of skill to additional nightmares } \\
\text { - Homework assignments } \\
\text { - Question and review }\end{array}$ \\
\hline
\end{tabular}

IRT: imagery rehearsal therapy 
자는 일주일 동안 4번 악몽을 꾸었으며, 주 평균 악몽 횟수 는 0.57 번이었다. 내담자는 수면 및 악몽 일지 작성에 있어 어려움은 없었으나 잠에서 깨지 않더라도 기분 나쁜 꿈 모 두 악몽 일지에 작성할 수 있도록 안내하였다. 이후 악몽과 수면에 대한 교육이 제공되었으며, 내담자는 높은 수용과 이 해를 보였다. 2회기에 내담자는 악몽 치료를 위한 중요한 기 술 두 가지를 학습하였다. 첫 번째로 즐거운 심상을 회기 내 에서 치료자와 함께 실시하고 연습하였다. 이는 3 회기의 악 몽 재구성 작업에 들어가기 전에, 많은 PTSD 환자들은 불안 정한 심상을 호소하기 때문에 악몽 재구성을 하기에 앞서 즐거운 심상부터 연습해야 한다. 치료 초기에 바로 악몽의 재구성을 시도하게 되면 부정적인 심상이 침투하여 오히려 치료의 조기 중단 및 임상적인 증상들이 증가될 수 있기 때 문이다. ${ }^{2}$ 회기 내에서 실시하게 되는 즐거운 심상은 오감을 사용하여 즐거운 장면을 떠올리는 작업을 하게 되는 것이다. 내담자는 즐거운 심상 연습에 있어 실제 다녀왔던 휴양지를 떠올리며 높은 교육 이해도를 보였으나, 연습하는 과정에서 부정적인 심상의 침습을 경험하였다. 즐거운 휴양지를 떠올 리는 와중, 하늘이 열리면서 검은 손이 모든 장면을 초토화 시키는 경험을 하며 어려움이 있다고 호소하였다. 회기 내에 서 부정적인 심상의 침습을 경험할 시에, 사용할 수 있는 네 가지 방안(중지하기, 심호흡하기, 내담자가 집중하고 싶은 긍정적인 심상에 대해 써보기, 그리고 인정하기와 선택하 기)에 대해 소개를 하며, 부정적인 침습 증상을 경험해도 긍 정적인 심상을 선택하고 다시 전환할 수 있는 개입을 시행 하였다. 두 번째로, 회기 내에서 이완요법 중 하나인 호흡요 법의 원리를 소개하고 치료자와 함께 단계별 호흡요법을 진 행하였다. 2회기 과제로 즐거운 심상 연습과 하루에 2 번 호 흡 연습을 계획하였다.

\section{3 회기}

내담자의 수면 및 악몽 일지, 즐거운 심상 연습, 호흡 과제 에 대해 검토 후 악몽 재구성 연습을 3회기에서 진행하였다. 내담자의 주 평균 악몽 횟수는 0.14 번으로 줄어들었다. 과제 에 있어 특별히 어려움을 보고하지는 않았으나 심상 연습 시 간을 호흡요법과 같은 시간에 이어 진행할 수 있도록 수정하 였다. 주로 3 회기에서는 즐거운 심상을 활용하여 악몽 재구 성을 하는 시간을 가졌다. 악몽 재구성이란, 기존에 반복적 으로 꾸던 악몽 한 개를 선택해서 악몽을 중립적이거나 긍정 적인 내용으로 새롭게 바꾸는 작업을 거친다. 악몽을 재구성 하는 과정에서 새로 구성되는 꿈은 악몽과 시작은 동일하게 유지하고, 악몽 중 가장 감정적으로 자극적인(예를 들어, 공 포를 가장 유발하는) 지점을 확인하게 한 후, 그 직전부터 내
용을 수정하는 작업을 진행하게 된다. 내담자가 선택한 악몽 은 학교에서 사람들이 내담자에 대해 수군거리고, 가해자가 나타나서 폭력을 휘두르려고 하는 무서운 얼굴을 보고 보통 잠에서 깨어난다고 하는 내용이었다. 이를 재구성하는 과정 에서, 학교로 들어가는 악몽의 초반 내용은 동일하게 유지하 되, 교실에 혼자 앉아있지 않고 좋아하는 친구들이 자신을 기다리고 있으며, 맛있는 음식들이 진열되어 있고 창밖으로 나무에 햇빛이 비추는 내용으로 재구성하였다. 더불어, 가해 자가 나타나게 되면 갑자기 폭포가 등장해 그가 폭포 밑으로 떨어지는 내용도 추가하였다. 회기 내 눈물을 보이던 내담자 는 악몽 재구성 연습 중 “좋아하는 사람들과 음식을 생각하 니 신나고 기분이 좋아졌다”고 보고하였다. 3 회기 과제는 해 당 악몽 재구성 내용을 토대로 매일 15 분씩, 재구성된 악몽 내용을 바탕으로 심상 연습을 하도록 안내하였다.

\section{4회기}

4 회기에서는 주로 재구성한 꿈 심상을 검토하고 내담자의 치료 경과에 따른 악몽 변화를 살펴보았다. 내담자의 경우 이전 회기보다 주 평균 악몽 횟수가 0.42 번으로 증가하였고, 악몽 재구성에 있어 부정적인 침습 증상을 호소하였다. 새롭 게 구성된 꿈의 내용이 긍정적인 내용으로 넘어가려고 할 때에 “흑백사진처럼 정지된 모습만 지나간다"라고 하며 어 려움을 호소하였다. 이런 어려움을 다루며, 새로운 꿈 내용 에서 본인의 마음에 안정을 줄 수 있는 단어에 집중하기("안 전하다") 그리고 새로 구성된 내용에 본인에게 가장 위안이 될 수 있는 존재를 추가하기(돌아가신 아버지)하여 기존의 재구성된 꿈 내용을 수정하고 연습을 반복하였다. 과제에 있 어 내담자의 심상 연습이 호흡요법에 비해 상대적으로 시간 을 적게 사용하는 것을 확인하여 1 회 심상 시 최소한 10 분 이상 연습할 수 있도록 피드백을 주었다. 3회기와 마찬가지 로 재구성한 꿈 심상시연 연습을 계획하였다.

\section{5 회기}

마지막 회기에서 내담자의 재구성한 꿈 심상을 검토한 후 재발 방지를 위해 유발 요인을 확인하였다. 내담자의 재구성 한 꿈 심상에 있어 수정이 필요한 사항은 없었으며, 심상 및 호흡 연습에 있어 매우 성실하게 진행한 점을 강화하였다. 내담자는 악몽 재구성 연습을 통해 이전 회기에서 선택한 악 몽의 내용이 재구성되는 것을 경험하였으며, 4 회기에서 진 행한 수정 사항으로 인해 악몽을 전혀 꾸지 않은 것을 볼 수 있었다. 내담자는 1회기 때 주 2 3회 악몽을 경험하였으나 현재 악몽을 전혀 경험하지 않는다고 보고하였다. 비록 내담 자가 악몽을 꾸지 않는다고 보고하였지만 유발 요인을 확인 
한 결과 대인관계 스트레스, 특히 가족 스트레스를 받을 때 악몽이 유발된다고 보고하였다. 이러한 유발 요인은 심상시 연치료 이후 내담자의 악몽 재발 가능성이 높다고 판단되어 대인관계 스트레스에 대처하는 방법에 대해 추가적인 회기 가 필요하였다. 마지막으로 치료를 진행하면서 학습한 심상 시연 기술을 다른 악몽에 적용시키는 방법에 대해 안내하였 고, 지속적으로 심상시연 기술을 사용할 것을 권장하였다.

\section{고 찰}

본 증례에서는 악몽장애 및 PTSD 공병 환자에게 외상 사 건을 다루지 않고 악몽에만 초점을 두어 심상시연치료의 효 과성을 확인하였다. 심상시연치료의 초반부는 악몽에 대한 교육으로 이루어졌으며, 후반부에서는 손상된 심상 체계를 치료하는 것으로 구성되었다. ${ }^{2}$ 내담자의 수면 패턴은 약 5 주 동안의 수면 및 악몽 일지를 작성하고, 매 회기마다 이에 대 한 문답을 진행하였다. 내담자는 수면 및 악몽에 대한 교육 과 함께 회기별로 즐거운 심상 연습, 호흡요법, 악몽 재구성, 재발 방지와 같이 주제를 나누어 기술을 습득하였다. 주간에 서의 일들은 수면 동안의 심상에 영향을 주기 때문에 주간 동안의 심상 연습은 치료 효과에 중요한 역할을 한다. ${ }^{8}$ 이에 회기에서 배운 기법을 과제로 내주어 주간 동안 반복적으로 연습하게 하였으며, 회기 내에서 한 주 동안의 과제 수행에 대해 다루었다. 이러한 작업은 내담자가 심상시연치료 이후 에도 언제든지 스스로 기술을 적용할 수 있게 해주며, 치료 자가 내담자의 과제 수행에 대해 격려하는 것이 중요하다.

본 증례의 내담자는 한 번도 빠짐없이 성실하게 과제를 수행하였다. 이에 내담자의 수면 및 임상 지표 모두 심상시 연치료 이후 향상된 것을 확인하였다(Table 2). 특히, 내담자 는 심상시연치료 이후 악몽을 더 이상 꾸지 않는다고 보고 하였고(Fig. 1), PTSD 심각도도 임상군에서 비임상군 범위 에 해당하는 점수로 감소하였다. 이는 외상을 다루지 않고 수면 문제인 악몽 증상에만 초점을 두어 치료적 개입을 하 여도 PTSD 증상이 완화될 수 있음을 시사한다. 더불어 우 울, 불안, 자살 심각도, 불면증 심각도 모두 정상 범위에 해 당하는 점수로 감소된 점(Table 2)을 통해 독립적인 수면장 애로서 악몽을 치료하는 심상시연치료가 다른 증상을 완화 시키는 데 있어서도 효과적임을 설명할 수 있다. 이는 악몽 에 대한 심리적 개입을 실시하였을 때, 악몽의 심각도뿐만 아니라 수면의 질, 불안, 우울, PTSD 심각도 수준이 감소하 고 이후에도 효과가 유지된다는 선행연구를 지지한다. ${ }^{9}$ 더불 어 잦은 악몽을 경험하는 사람일수록 불안, 우울, 자살 사고 등의 정신적 고통과 높은 관련성이 있다. ${ }^{10}$ 따라서 다른 정신
질환과 악몽장애가 공병으로 존재할 때, 악몽에 초점을 맞춘 근거 기반의 심상시연치료를 진행하는 것이 필요하다.

내담자는 심상시연치료를 통해 악몽의 감소 및 임상지표 의 개선을 보이긴 했지만, 여전히 수면 효율성은 $50 \%$ 로 낮 은 편이었다. 악몽장애와 함께 불면증 증상도 함께 호소했기 때문에, 향후 불면증 및 악몽장애를 동시에 호소하는 환자를

Table 2. Clinical index \& sleep indices before and after IRT

\begin{tabular}{lcc}
\hline $\begin{array}{c}\text { Clinical and sleep } \\
\text { indicators }\end{array}$ & Before IRT & After IRT \\
\hline Clinical index & & \\
BDI & 24 & 13 \\
BAI & 25 & 10 \\
PCL-5 & 48 & 10 \\
ISI & 20 & 7 \\
DSI-SS & 4 & 1 \\
DDNSI & 15 & 0 \\
NES & 10 & 0 \\
Sleep indices & & \\
BT & $10: 32 \mathrm{pm}$ & $1: 09 \mathrm{am}$ \\
WT & $7: 51 \mathrm{am}$ & $6: 47 \mathrm{am}$ \\
SE (\%) & 32.18 & 53.54 \\
WASO (min) & 318.50 & 11.43 \\
SOL (min) & 143.00 & 42.86 \\
TIB (min) & $609.00 \pm 14.14$ & $376.00 \pm 123.73$ \\
TST (min) & $196.00 \pm 90.51$ & $216.43 \pm 132.56$ \\
NF & 4 & 0 \\
ND & 3 & 0 \\
\hline
\end{tabular}

IRT: imagery rehearsal therapy, BDI: Beck Depression Inventory, BAI: Beck Anxiety Inventory, PCL-5: PTSD Checklist for DSM-5, PTSD: posttraumatic stress disorder, DSM-5: Diagnostic and Statistical Manual of mental disorders Fifth edition, ISI: Insomnia Severity Index, DSI-SS: Depressive Symptom Inventory-Suicidality Subscale, DDNSI: Disturbing Dream and Nightmare Severity Index, NES: Nightmare Effects Survey, BT: bed time, WT: wake time, SE: sleep efficiency, WASO: wake after sleep onset, SOL: sleep onset latency, TIB: time in bed $(\mathrm{M} \pm \mathrm{SD})$, TST: total sleep time $(\mathrm{M} \pm \mathrm{SD}), \mathrm{SD}$ : standard deviation, NF: nightmare frequency, ND: nightmare distress

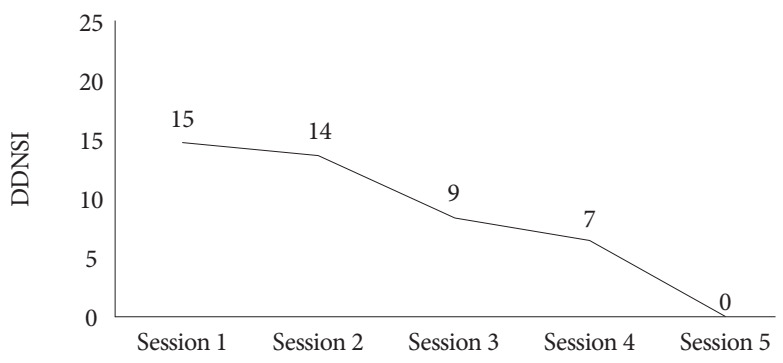

Figure 1. Nightmare severity score graph by session. DDNSI: Disturbing Dream and Nightmare Severity Index. 
치료할 시에 불면증의 근거기반치료로 알려져 있는 불면증 을 위한 인지행동치료도 같이 시행하여 수면 효율성을 높이 는 방법도 고려할 필요가 있다. 실제로 선행연구에서 트라우 마 환자에게 불면증을 위한 인지행동치료와 심상시연치료를 같이 시행하는 것이 효과성을 상승한다고 보고된 바 있다. ${ }^{5}$

본 증례의 제한점은 액티그래피를 이용한 객관적인 수면 평가가 이루어졌으나 기계의 고장으로 데이터를 활용할 수 없어 내담자가 제출한 수면 일지를 통해 수면 지표의 자료 를 수집하였다. 또한 PTSD가 있는 악몽장애 환자의 단일 사 례 연구로 진행되었기에 이 연구 결과를 일반화하여 적용하 기 어렵다. 따라서 향후 연구에서는 객관적인 수면 평가가 함께 이루어지며, 연구 대상자의 참여 인원을 증가시킬 뿐만 아니라 다양한 증상을 가진 악몽장애 환자를 대상으로 심상 시연치료를 시행한 연구가 필요할 것으로 사료된다.

국외의 증례에서 보고된 악몽장애를 위한 심상시연치료 는 대개 성폭행 생존자, 참전 군인과 같이 외상 사건을 겪은 사람들에게 있어 질적 연구가 수행되었다. 이에 국내 처음으 로 신체적, 언어적, 성적 외상을 겪은 증례의 심상시연치료 경과에 대해 보고하였다. 선행연구와 마찬가지로 본 증례의 악몽에 대한 치료 효과는 객관적인 수치뿐만 아니라 주관적 보고로도 확인 가능하였다. 이는 국내에서도 심상시연치료 가 악몽을 치료하는 데 있어 효과적임을 반복 검증한 결과 이다. 현재 국내 악몽장애 환자에 대한 연구가 부족한 실정 이며, 악몽에 대한 진단과 근거기반 치료적 개입을 시행할 전문가 또한 부재한 상황이다. 본 연구는 국내 첫 심상시연 치료를 통해 악몽장애 환자의 수면 문제와 심리적 증상이 개선되는 것을 살펴본 점에서 의의를 가지며, 악몽을 경험하 는 사람에게 있어 심상시연치료를 활용할 수 있으며 그 중 요성에 대해 시사하는 바이다.

\section{Conflicts of Interest}

The authors have no potential conflicts of interest to disclose.

\section{Acknowledgments}

This work was supported by the Sungshin Women's University Research Grant of 2019-1-86-005.

\section{ORCID iDs}

Soyeong Park Su Jung Choi Eun Yeon Joo

Sooyeon Suh https://orcid.org/0000-0002-9512-5177 https://orcid.org/0000-0003-2171-7441 https://orcid.org/0000-0003-1233-959X https://orcid.org/0000-0003-0644-8634

\section{Author Contributions}

Conceptualization: Sooyeon Suh. Formal analysis: Soyeong Park. Investigation: Soyeong Park, Sooyeon Suh. Methodology: Soyeong Park, Sooyeon Suh. Resources: Su Jung Choi, Eun Yeon Joo, Sooyeon Suh. Writing-original draft: Soyeong Park. Writing-review \& editing: Su Jung Choi, Eun Yeon Joo, Sooyeon Suh.

\section{REFERENCES}

1. American Psychiatric Association. Diagnostic and Statistical Manual of Mental Disorders, 5th Edition (DSM-5). Washington: American Psychiatric Publishing, 2013.

2. Krakow B, Zadra A. Clinical management of chronic nightmares: imagery rehearsal therapy. Behav Sleep Med 2006;4:45-70.

3. Bootzin RR, Nicassio PM. Behavioral treatments for insomnia. In: Michel H, Richard ME, Peter MM. Progress in behavior modification. Vol. 6. New York: Academic Press, 1978;1-45.

4. Levin R, Fireman G. Nightmare prevalence, nightmare distress, and self-reported psychological disturbance. Sleep 2002;25:205-212.

5. Casement MD, Swanson LM. A meta-analysis of imagery rehearsal for post-trauma nightmares: effects on nightmare frequency, sleep quality, and posttraumatic stress. Clin Psychol Rev 2012;32:566-574.

6. Milad MR, Orr SP, Pitman RK, Rauch SL. Context modulation of memory for fear extinction in humans. Psychophysiology 2005;42:456-464.

7. Lee C, Shin S. Standardization of the Mini-Mental State Examination (MMSE) in Korea. J Korean Neuropsychiatr Assoc 1993;32:950-61.

8. Malouff JM, McGee JA, Halford HT, Rooke SE. Effects of pre-competition positive imagery and self-instructions on accuracy of serving in tennis. J Sport Behav 2008;31:264-275.

9. Hansen K, Höfling V, Kröner-Borowik T, Stangier U, Steil R. Efficacy of psychological interventions aiming to reduce chronic nightmares: a meta-analysis. Clin Psychol Rev 2013;33:146-155.

10. Nadorff MR, Nazem S, Fiske A. Insomnia symptoms, nightmares, and suicide risk: duration of sleep disturbance matters. Suicide Life Threat Behav 2013;43:139-149. 